\title{
Current and Future Directions for Integrative Health and Healing: A Summary of the NATO HFM 195 TASK FORCE
}

\author{
Richard P. Petri, Jr., MD, FAAPMR, FAAIM, COL MC, ${ }^{1, *}$ Fred Zimmermann, MA, CPT, ${ }^{2, * *}$ \\ Marion Trousselard, MD, PhD, ${ }^{3, * * *}$ and Richard C. Niemtzow, MD, PhD, MPH, COL (Ret) USAF, MC, FS ${ }^{4, *}$
}

\begin{abstract}
Background: Simply put, medicine is culturally based and alternative medicine is a polarizing field. However, because healthcare delivery systems must constantly change to meet societal healthcare needs, consideration of different cultures and perspectives must occur to develop new paradigms in healthcare delivery. Integrative health and healing $\left(\mathrm{IH}_{2}\right)$ offers a model of holistic care that has potential substantial benefit for military organizations. Objective: This article is a summary of the results and recommendations of the NATO Task Force HFM 195, Integrative Medicine Interventions for Military Personnel.

Methods: This overview discusses the findings and recommendations of the NATO Task Force on Integrative Medicine Modalities for Service Members. Next steps and quick wins with the implementation of meditative and acupuncture techniques are discussed.

Conclusions: The NATO Task Force HFM-195 was formed to evaluate the current status of complementary and integrative medicine (CIM) within the military units of the NATO participating countries. The Task Force recommends that $\mathrm{IH}_{2}$ offers a new perspective on healthcare delivery in military organizations. Specifically, this includes implementation of selected $\mathrm{IH}_{2}$ practices; development of educational programs for patients, providers, and policy makers; and review of clinical outcomes and best practices. Collaborative research partnerships need further exploration.
\end{abstract}

Key Words: Complementary and Alternative Medicine, Integrative Health and Healing, Integrative Medicine, NATO, Task Force

\section{INTRODUCTION}

"It is more important to know what sort of person has a disease than to know what sort of disease a person has.",I Hippocrates
IMPLY PUT, MEDICINE is culturally based and alternative $\checkmark$ medicine is a polarizing field. However, because healthcare delivery systems must constantly change to meet societal healthcare needs, consideration of different cultures and perspectives must occur to develop new paradigms

\footnotetext{
${ }^{1}$ Chairman, NATO HFM-195 Task Force, Integrative Medicine Interventions for Military Personnel, United States Army, El Paso, TX.

${ }^{2}$ Generation Research Program (GRP), Human Science Center, University of Munich, Bad Toelz, Germany.

${ }^{3}$ Institute of Biomedical Research, Armies' Health Service, Bretigny sur Orge, France.

${ }^{4}$ Director, USAF Acupuncture and Integrative Medicine Center, Joint Base Andrews, MD.

This article was prepared as part of the work product of NATO Science and Technology Organization, Task Force, Human Factors and Medicine (STO-TR-HFM) 195, Integrative Medicine Interventions for Military Personnel.

*The opinions and assertions contained herein are the private views of the author and are not to be construed as official or as reflecting the views of the United States Army Medical Corps, the Army at large, or the Department of Defense.

**The opinions and assertions contained herein are the private views of the author and are not to be construed as official or as reflecting the views of the German Army.

***The opinions and assertions contained herein are the private views of the authors and are not to be construed as official or as reflecting the views of the French Armed Forces Biomedical Research Institute or the French Military Health Service at large.
} 
in healthcare delivery. Therefore, over the past 5 decades, a new paradigm, called alternative medicine, has been emerging. Like healthcare, alternative medicine has "matured" as the knowledge of the related practices and science becomes better understood. Thus, the nomenclature has changed to reflect the evolutionary process: from alternative to complementary to integrative medicine to integrative health and healing, with the latter term as suggested in this report. The polarization is therefore reduced somewhat.

Effecting changes to long-standing cultures is difficult. It is even more difficult to change military medicine because it abuts two cultures: that of medicine and that of the military. Integrative health and healing $\left(\mathrm{IH}_{2}\right)$ offers a model of holistic care that has potential significant benefit for military organizations, a model that embraces the cultures of medicine and military.

Improvements to the world's healthcare systems will benefit both the individual and the collective whole. Collaborative teams must develop a pluralistic healthcare system of understanding, listening, guidance, and respect. Cultural fluency has been defined as "having the capacity to embrace and flow within many various cultural environments, and the ability to utilize diversity for understanding and growth." 2 Thus, cultural fluency can be used to guide the establishment of a new military model of health and healing through the expansion of viewpoints. This will only lead to improved outcomes.

Multinational organizations such as NATO are the best place to begin these partnerships. The new healthcare paradigm should be void of hierarchical structures with the understanding that there is no single correct system. The paradigm incorporates treatments plans designed for individuals. A treatment program that best suits and treats the patient is the correct one. This is achieved only when all options are considered. The countries within the NATO framework offer differing cultural perspectives, experiences, and philosophies that collectively will benefit all organizations. Therefore, the NATO Task Force is the first step to opening this door to improved global military health and healing.

\section{CULTURAL CONCEPT OF HEALTHCARE SYSTEMS: THE NEED TO UNDERSTAND AND EMBRACE}

The culture of a society is embedded within the healthcare systems of that society. This has been true since ancient times. As a result of globalization of the world, the differences in cultures and healthcare systems become more apparent. Adding to the complexity, healthcare systems used to treat military members must adapt to the military culture to be effective within the military framework. Leveraging the NATO military perspectives of differing healthcare systems will lead to improvements for all systems.
Table 1 compares the cultural aspects of global healthcare systems, specifically from the "Western" and "Eastern" points of view. Although tables give visible structure to a discussion, there are limitations. A two-column table would be oversimplified. It would fail to illustrate that differing healthcare systems are not represented as an either/or choice but rather that systems should flow from one to another. Thus, a third column has been added. This center column represents this flow from one system to another; however, the descriptors need to be developed as the new paradigm of healthcare emerges.

Thus, the table reinforces the concept that healthcare systems are complex and require multidimensional views and explanations. There are hundreds of treatments, systems, approaches, and subspecialties. Many of these are culturally based. Some are full medical treatment systems. Others are simple techniques that can be used in specific situations. The list of "what is what" can go on and on. Certainly, many systems cannot be honestly and adequately compared to others because labeling is artificial, grouping is artificial, and comparisons are artificial. Often, attempts to label, group, and compare reveal biases, prejudices, ignorance, and misunderstandings. However, attempts to identify new means of delivering health and healing must be undertaken. Simply stated, improvements to all systems are needed. Over the past few decades, there have been meaningful strides and efforts toward this. The NATO Task Force on Integrative Medicine is evidence of this. As the system is evaluated and critiqued, flexibility in understanding and acceptance of difference is an upmost necessity. Table 1 is a first step to provoke intellectual and emotional discussions. The hope is that as a result, there will be an understanding of each system's value and a cooperative willingness to consider change. Ultimately, patients will benefit from the larger available "toolbox" of treatment options to meet their needs and goals of health and healing.

\section{INTEGRATIVE HEALTH AND HEALING PRACTICES}

A clinic or center that provides just acupuncture, meditation, yoga, and other such integrative medicine modalities is an integrative center in name only. Numerous hospitals, centers, clinics, and healthcare systems that have incorporated integrative medicine into practice have failed for various reasons: the lack of political and financial support, challenges with credentialing and privileging status, standards with educational requirements, sparse evidence-based science, and a system of fragmented care. ${ }^{3,4}$ These barriers must be overcome with continued well-designed research and policies that result in improved political and financial support and acceptance. However, the manner in which a treatment is provided is the crucial challenge to developing a truly $\mathrm{IH}_{2}$ practice. Therefore, fragmentation of care must 
Table 1. Cultural Aspects of Global Healthcare Systems

\begin{tabular}{|c|c|c|c|}
\hline Aspect & Biomedical construct & $\begin{array}{c}\text { Balance between } \\
\text { the two systems }\end{array}$ & Relational construct \\
\hline Terms* & $\begin{array}{l}\text { Allopathic, Western, standardized, } \\
\text { scientific, modern, conventional, } \\
\text { ontological, materialistic }\end{array}$ & & $\begin{array}{l}\text { Eastern, alternative, complementary, } \\
\text { integrative, traditional, holistic, non- } \\
\text { materialistic, homeodynamic }\end{array}$ \\
\hline $\begin{array}{l}\text { Described } \\
\text { in terms of }\end{array}$ & Nouns (states of being) & & Verbs (dynamism and balance) \\
\hline $\begin{array}{l}\text { Embedded } \\
\text { theories }^{\dagger}\end{array}$ & $\begin{array}{l}\text { Reductionist, categorical, Newtonian } \\
\text { physics, Cartesian, mind-body } \\
\text { dualism, rationalized }\end{array}$ & & $\begin{array}{l}\text { Holistic, quantum physics, } \\
\text { nonscientific, patient-centered, } \\
\text { relational }\end{array}$ \\
\hline View of body & Mechanical, machine, "body", & & $\begin{array}{l}\text { Psychosocial, energetic process, } \\
\text { spiritual, "mind," person, body- } \\
\text { person }\end{array}$ \\
\hline Examples $^{\S}$ & $\begin{array}{l}\text { "Western", specialties and } \\
\text { subspecialties (e.g., cardiology, } \\
\text { internal medicine, orthopedics) }\end{array}$ & & $\begin{array}{l}\text { Curanderismo, TCM, Ayurveda, } \\
\text { psychiatry, shamanism }\end{array}$ \\
\hline Focus & $\begin{array}{l}\text { Objective, measureable phenomena and } \\
\text { technology to achieve a diagnosis; } \\
\text { abnormality based on "standardized } \\
\text { ranges"; organ/system centered }\end{array}$ & & $\begin{array}{l}\text { Individuality and why this person has } \\
\text { this condition at this time }\end{array}$ \\
\hline Treatment focus & $\begin{array}{l}\text { Distinct disease entity (symptom- } \\
\text { related illness) }\end{array}$ & & $\begin{array}{l}\text { Restoration of balance (energetic flow } \\
\text { and homeodynamic) }\end{array}$ \\
\hline Body focus & $\begin{array}{l}\text { Physical body (organ, tissue, cellular } \\
\text { level) }\end{array}$ & & $\begin{array}{l}\text { Energetic (vital spirit, Qi, ch'i, ki, } \\
\quad \text { prāna }) \text {, psychosocial, social bodies }\end{array}$ \\
\hline $\begin{array}{l}\text { Model of disorder } \\
\text { (primarily) }\end{array}$ & $\begin{array}{l}\text { External (pathogens, environmental } \\
\text { impact on individual) }\end{array}$ & & $\begin{array}{l}\text { Internal energetic imbalances, } \\
\text { dysfunction (disruptive flow and } \\
\text { homeodynamics) leading to somatic } \\
\text { disease }\end{array}$ \\
\hline $\begin{array}{l}\text { Underlying issues } \\
\text { for seeking } \\
\text { treatment }\end{array}$ & $\begin{array}{l}\text { Disease, pathogenic origin with } \\
\text { distinctive symptoms/signs, single } \\
\text { causes, specific treatments }\end{array}$ & & $\begin{array}{l}\text { Deep-rooted causation, multiple-level } \\
\text { energetic imbalances }\end{array}$ \\
\hline Entry point & $\begin{array}{l}\text { Trauma, acute illness, end-stage } \\
\text { physical malfunction, minimal } \\
\text { preventive care }\end{array}$ & & $\begin{array}{l}\text { Presomatic/physical manifestation of } \\
\text { energetic dysfunction/imbalance, } \\
\text { wellness, preventive care }\end{array}$ \\
\hline $\begin{array}{l}\text { Variability of } \\
\text { disorder }\end{array}$ & $\begin{array}{l}\text { All individuals react in the same way to } \\
\text { the same pathogen (e.g., diabetes is } \\
\text { diabetes in all individuals with the } \\
\text { disease) }\end{array}$ & & $\begin{array}{l}\text { Each individual reacts differently from } \\
\text { others and temporally with self }\end{array}$ \\
\hline $\begin{array}{l}\text { Individual locus of } \\
\text { control }\end{array}$ & Passive & & Active, responsible \\
\hline Treatment & $\begin{array}{l}\text { Disease-based (e.g., hypertension } \\
\text { requires antihypertensive } \\
\text { medication) }\end{array}$ & & $\begin{array}{l}\text { Individualistic (individual's energy/ } \\
\text { constitution lead to the imbalance), } \\
\text { Law of Cure } 11^{* *}\end{array}$ \\
\hline Death & Failure of treatment & & Natural outcome for some \\
\hline $\begin{array}{l}\text { Provider } \\
\quad \text { participation }\end{array}$ & Authoritative & & Facilitator \\
\hline Therapeutic goal & $\begin{array}{l}\text { Cure, recent emphasis on management } \\
\text { of disease }\end{array}$ & & Healing, wellness, quality of life \\
\hline $\begin{array}{l}\text { Education of } \\
\text { practitioner }^{\|}\end{array}$ & $\begin{array}{l}\text { Formal education with examination at } \\
\text { discrete steps, legal criteria for } \\
\text { practice }\end{array}$ & & $\begin{array}{l}\text { Apprenticeship with evaluation of } \\
\text { quality of care determined by } \\
\text { preceptor and community } \\
\text { Formal education with examination at } \\
\text { discrete steps, legal criteria for } \\
\text { practice }\end{array}$ \\
\hline Research model ${ }^{\natural}$ & $\begin{array}{l}\text { Randomized, placebo-controlled, } \\
\text { double-blind trial, "evidence based" }\end{array}$ & & $\begin{array}{l}\text { Model validity, whole systems } \\
\text { research, mixed methods research, } \\
\text { "evidence based" }\end{array}$ \\
\hline
\end{tabular}


TABLE 1. (CONTINUED)

\begin{tabular}{|c|c|c|c|}
\hline Aspect & Biomedical construct & $\begin{array}{c}\text { Balance between } \\
\text { the two systems }\end{array}$ & Relational construct \\
\hline Practice type & $\begin{array}{l}\text { One practitioner/one patient at a time, } \\
\text { community-based, hospital, home } \\
\text { care }\end{array}$ & & $\begin{array}{l}\text { One practitioner/one patient at a time, } \\
\text { community-based, hospital, home } \\
\text { care }\end{array}$ \\
\hline Challenges & $\begin{array}{l}\text { Chronic illness, degenerative } \\
\text { conditions, stress-related disorders, } \\
\text { technology-based, tends to be high } \\
\text { cost }\end{array}$ & & $\begin{array}{l}\text { Acceptance by dominant allopathic } \\
\text { systems, minimally evidence-based } \\
\text { based on biomedical perspectives }\end{array}$ \\
\hline Ultimate goal & Care of the patient & Care of the patient & Care of the patient \\
\hline
\end{tabular}

TCM, Traditional Chinese Medicine.

- Defining medical systems is nearly impossible, especially when the definitions are confined to a bimodal pattern. The terms used are those found in the literature, related to each of the main categories. Every term presents a potential source of critiques and challenges. Many could be used in both columns. As an example, using the term "standardized" for biomedicine is more of an attempt to place biomedicine in a position over other forms of medical care. This is not the reality. Additionally, "standardized medicine" has not been proven to be "good" or "safe" in all cases. The incidences of iatrogenic harm from standardized treatments confirm this. As a result, numerous organizations have evaluated "standardized practices" and recommended steps to improve safety and effectiveness. Further, no individual treatment is truly holistic. When relational treatments are used in isolation, the paradigm of holistic care is missed. This is a significant potential pitfall for the relational treatments (i.e., using a relational treatment can lead to the misunderstanding that one is treating in a holistic approach, just because the treatment term is from the right-sided column).

**Constantine Hering described healing in terms of the concept known as the law of cures. Although Dr Hering was a homeopath, the law of cures can be applied to any system. Specifically, healing occurs

1. Symptoms heal from the deepest (most limiting) level to the most superficial. This means often from the mental into the emotional and finally into the physical, although it can also be simultaneous on two or more levels.

2. Symptoms resolve in the reverse order that they came: the most recent going away first.

3. Symptoms should improve from above downwards.

4. Symptoms heal from the most important organ to the least important organ (i.e. generally from the heart to the skin which is the most superficial organ).

5. Symptoms improve from the center of the body to the periphery (hands and feet)

"Scientific endeavor is deeply embedded in the "randomized controlled trial [RCT]" approach of research to describe acceptable practice. However, observations, experience, and analytic and clinical assessments nonetheless add valuable information. At times, it is the only means to gain insight. The medical field continues to support RCTs to define the effectiveness, safety, and acceptability of a modality. However, RCTs cannot adequately address many of the relational modalities. That approach just doesn't fit. All represent science. Therefore, neither side of the table is truly "nonscientific" despite the appearance the table gives.

*With time, the biomedical construct has been forced to understand that the body without the mind is an inadequate view of the paradigm. Viewing outcomes in a singular term did not lead to an understanding of how the effect was achieved. Therefore, a broader view of the "body" and "something else" was developed. This includes concepts of "placebo" and "suggestion" to help define the construct. In the relational construct, the emphasis has been on the response of the "whole." That is to say, a medication used to treat hypertension, which works on the cardiovascular system (biomedical thinking), has an effect on the entire person as well as the supportive community of the individual. A way to understand this is to understand that persons with well-controlled hypertension may bring happiness to their family and friends because they can now participate in shared-interest activities. The relational model recognizes that both interactions and interventions affect the patient; biomedicine minimizes interactions and emphasizes interventions.

${ }^{\S}$ Biomedicine reduces itself into specialties, such as cardiology and orthopedics. Each in isolation is not a fully formed medical system. This is the hallmark of reductionism. Relational modalities can have subspecialization as well. However, many of terms in the right column represent "world medical systems." Some of these systems are whole medical care practices. Thus, it is difficult for any type of comparison of the two models. Those involved in the biomedical construct put "all other systems that are not biomedical" in the relational construct. This is an example of the fallacy that because something doesn't fit in one category, it automatically fits into the other and subsequently there is an appropriate direct comparison.

"The use of the apprenticeship approach can be locale and medicine specific. However, this approach is becoming rare for any system training. In fact, internships and residencies (biomedical construct) are, in the true definition, types of apprenticeships (system of training a new generation of practitioners of a trade with on-the-job training and accompanying studies).

"The term "evidence-based" applies to both constructs, although the perspective of what is evidence based may different depending on the point of view.

be addressed and resolved. As Rakel and Weil write, "Simply adding CAM therapies without changing our healthcare model is like increasing the number of specialists with no primary care infrastructure, an approach that increases cost and reduces the quality of care." 5

$\mathrm{IH}_{2}$ practices must provide the "milieu of care" that embraces the true integrative philosophy and concepts of participation, responsibility, and empowerment. This ap- plies not just to the integrative modalities. It also applies to the entire treatment plan, whether that includes acupuncture, medications, or surgery. The whole system must be set up so that the patient "flows" within the system of well-coordinated healthcare instead of our current disjointed system of appointments across several specialties. Modalities need to complement each other instead of "competing" with offsetting side effects and results. 
Individuals need to be empowered to be truly active and not passive. $\mathrm{IH}_{2}$ practices can leverage the philosophy of developing health behaviors by promoting individuals' resources that improve understanding of health and personal development. The participant as well as the system itself must be empowered to provide the best care for the optimal outcomes.

Cure is not the determinant of success; rather, an improved quality of life, which supports the process of healing, is the measure of success. Curing is often misinterpreted as healing. This is not to say that curing cannot be healing; however, curing is often perceived to have removed the origin of the disease when it fact it often only removes the obvious symptoms of the illness. Healing occurs when the patient begins to be aware of the causal factors that led to the disease processes (i.e., the root causes). In the current "Western" paradigm, we excel at symptom management instead of assisting with awareness of cause. We must now begin to excel at health and healing and align our strategic and operational actions to the holistic perspective that underlies a healthcare system based on $\mathrm{IH}_{2}$. Figure 1 shows a NATO Task Force-proposed matrix illustrating the use of integrative medicine modalities for service members from prevention to intervention.

Throughout the NATO medical systems and communities, new methods of practice are being used and evaluated. Examples of this include the U.S. Department of the Army's Interdisciplinary Pain Management Centers, which are devoted to a holistic approach to pain. ${ }^{6}$ The French Military Fire Fighters are using stress management programs based on cognitive and emotional interventions for stress perception and reactivity. The reader is referred to the article in this issue of the journal titled "Tactics to Optimize the Potential and CardioBioFeedback in Stress Management: The French Experience" for details. The use of mindfulness practices (see the article in this issue titled "Mindfulness Based Practices as a Resource for Health and Well Being" for details) and the concept of spirituality/ religiosity $^{7}$ for health, well-being, and adaptive coping resources are under evaluation within the German military. Finally, battlefield acupuncture and auricular trauma protocol are used by several militaries for the treatment of pain and early manifestations of post-traumatic stress, especially following an exposure to a major trauma or disaster. ${ }^{8}$

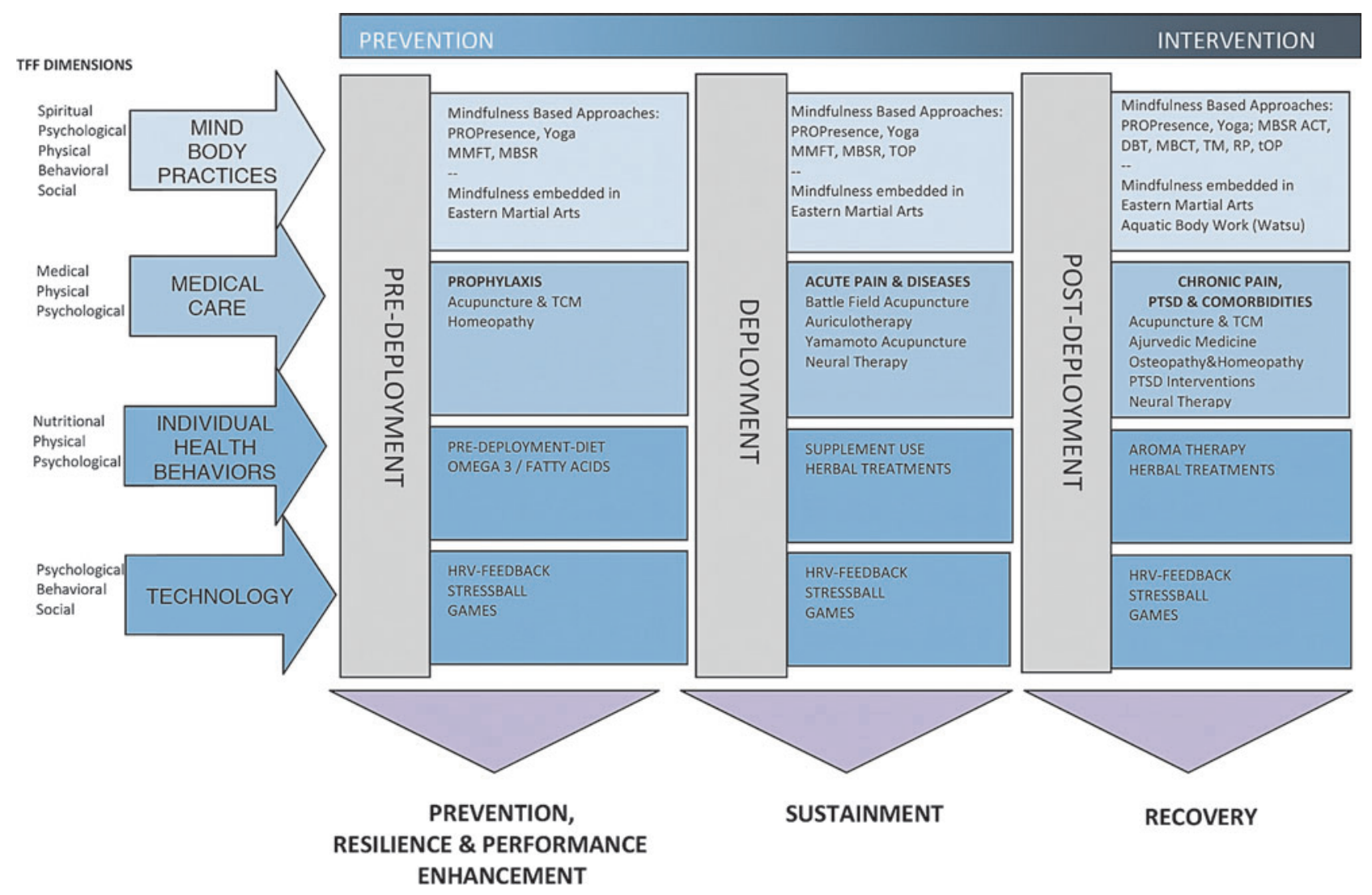

FIG. 1. Proposed matrix for integrative medicine treatments. HRV, heart rate variability; MMFT, Mind Fitness Training Institute; MBSR, mindfulness-based stress reduction; MBSR ACT, MBSR with acceptance and commitment therapy; PTSD, post-traumatic stress disorder; RP, relapse prevention; TCM, Traditional Chinese Medicine; TFF, total force fitness; TOP, Tactics to Optimize the Potential; TM, Transcendental Meditation. 
Some collaborative projects resulting from the NATO meetings include (1) a French-German collaboration to explore relationships between mindfulness and life satisfaction and stress levels, (2) the evaluation of the cultural differences in rates of post-traumatic stress disorder based on psychological factors in the International Security Assistance Force troops, and (3) a French-German collaboration on the beneficial resources and unmet psychosocial and spiritual needs of military personnel.

\section{DISCUSSION}

The overreaching construct of a paradigm of $\mathrm{IH}_{2}$ cannot be developed within the confines of a single Task Force Group. The basic goal of the Task Force was to review the current state of CIM, or $\mathrm{IH}_{2}$ within the global healthcare system, particularly that of the NATO participant countries.

\section{An Exploratory Task Force}

This Task Force, HFM-195, Integrative Medicine Interventions for Military Personnel, was primarily of an exploratory nature. World healthcare systems, such as Traditional Chinese Medicine, Ayurveda, and Tibetan medicine, were explored as potential models of new perspectives on healthcare delivery. Modalities such as mindfulness, meditation, acupuncture, spirituality, religiosity, mascots, protective environments, nutrition/supplementation, and yoga were discussed with particular emphasis on the use within military healthcare systems. Paradigm shifts using systems approaches and the concept of personalized medicine for resiliency, trauma spectrum disorder, pain, and stress disorders were introduced as a system of health and healing instead of the current system of disease management.

Common themes emerged from the NATO Task Force HFM-195. First, the use of $\mathrm{IH}_{2}$ modalities is common, although statistics showed significant variations. Second, the most challenging barrier for $\mathrm{IH}_{2}$ is the lack of standard, accepted terminology. This lack of uniformity affects communications, collaborations (clinical, research, education), regulatory policy development, reimbursements, acceptance, and comparative evaluations. This is a muchneeded first step. Third, the increasing popularity of integrative medicine modalities has been due to consumer demand. Policy makers need to recognize the rationale for the dissatisfaction with the current healthcare system. Openminded discussions with all stakeholders will only result in improved systems of healing. Fourth, several modalities can be implemented into the military systems, with evidence that the treatments are safe, cost-effective, and efficacious for the military population. These include acupuncture, particularly battlefield acupuncture; mindfulness/meditation; and movement/yoga. At the same time, international regulations, credentialing policies, education requirements, treatment protocols, tiered provider-level approaches, and research opportunities relevant to NATO, as well as appropriate recommendations, must be thoroughly reviewed for these modalities. Fifth, financial consideration of healthcare is paramount given the ever-decreasing military and national budgets. $\mathrm{IH}_{2}$ modalities offer high-touch, low-cost, safe, and effective treatment options. Therefore, the financial burden that medical healthcare imposes on budgets and the potential effect of $\mathrm{IH}_{2}$ on those budgets need to be evaluated.

Finally, pain and stress-related conditions are high-value targets for implementation of $\mathrm{IH}_{2}$ modalities. These conditions affect a substantial portion of the military personnel and place a large financial burden on the overall system. Therefore, specific programs for the treatment of pain and stress-related conditions need to be implemented and monitored.

\section{The Need for Collaborations}

As new practices are refined and researched, new policies, standards, and guidelines will be established. Currently, envelopes are being pushed. Limits are being stretched. And the status quo is being challenged. The pushing, the stretching, and the challenging must continue if the current medical systems will have any success with sustainability or if the patient's health is to be improved. However, few international, collaborative efforts are being made to define terminology, leverage best practices, maximize the coordination of efforts, develop research partnerships, or adopt strategic policies. Such partnerships would improve global health. International collaborations need to occur.

\section{RECOMMENDATIONS}

The NATO Task Force HFM 195 made recommendations based on the broad categories of clinical, educational, and research aspects.

\section{Clinical Aspects}

Implement multinational programs of those modalities with minimal side effects and potential benefit to the individual and military organizations, such as yoga, mindfulness, movement, biofeedback, and battlefield acupuncture. Concurrently, an international core of professionals or subject matter experts should be developed. Once established, "train the trainer" programs should be taught to minimize expenditures and maximize resources of local experts. Battlefield acupuncture and mindfulness programs could easily be implemented quickly and widely in the proposed manner. Throughout, the monitoring of best practices and outcomes, with recommendations and modifications as indicated, is necessary. 


\section{Educational Aspects}

Handbooks, guides, and pamphlets for service members, practitioners, and leadership should be written. Examples could be "A Service Member's Guide to Meditation Techniques" or "Vital Information a Commander Needs to Know About Integrative Health and Healing.' These instructional aids would educate patients on modality use and proper techniques, explore the various perceptions regarding $\mathrm{IH}_{2}$, or explain the importance of a shift in practice. Further, information and education on the importance of military culture and its uniqueness could be addressed so modalities could be adapted for optimal acceptance and utilization within a military framework.

\section{Research Aspects}

International collaborations in multiple areas of research are necessary. Multicenter and multicultural studies would yield valuable information not obtainable from a singlecenter study. Potential areas of research include the financial benefits of $\mathrm{IH}_{2}$ inclusion in the current healthcare systems, comparative cost-effectiveness of various modalities and for various conditions, and effect and benefits of $\mathrm{IH}_{2}$ on the collective (such as military unit cohesion, readiness, resiliency, and overall unit performance) as well as individual (such as an improved sense of well-being and quality of life and the social impact for the individual). Collaborations with other NATO task forces, hospitals/healthcare centers, academia, and international organizations should be sought out.

\section{REMAINING QUESTIONS}

In the final analysis, the Task Force had more questions than answers. This suggests that further investigations with additional task forces, symposia, or conferences are indicated. The following is a list of some of the questions raised by the Task Force.

1. What is acceptable terminology of $\mathrm{IH}_{2}$ and related practices?

2. How can international cultural and perspective differences be used to develop improved global healthcare?

3. How is $\mathrm{IH}_{2}$ accessed in and out of the military healthcare systems?

4. What are the costs to implement $\mathrm{IH}_{2}$ practices?

5. How will $\mathrm{IH}_{2}$ affect the organization and the individual?

6. Can other partners fund the implementation? International versus national?

7. What is the broader economical context to family and society? Can this be used to leverage civilian partnerships?
8. How should the continuity of care from active duty to veteran be managed to include partnerships between military and civilian agencies?

9. Can the integrative medicine modalities be translated into an active exercise (i.e., passive versus active participation)?

10. How can $\mathrm{IH}_{2}$ be used in developing the "new normal" for injured service members?

11. How can bias be minimized to allow for the best practices to be implemented both at individual and policy levels?

12. How can $\mathrm{IH}_{2}$ fit into the current healthcare systems as complementary (e.g., pharmacologic interventions or surgical procedures)?

13. $\mathrm{Can} \mathrm{IH}_{2}$ alter addiction and suicide rates?

14. Can cultural differences and experiences between countries help to treat difficult conditions? Can overlapping systems help to explain condition treatment failures?

15. Could personalized medicine benefit the current system?

\section{CONCLUSIONS}

Use of CIM is increasing among civilian and military populations. Financial support and standardized policy regarding CIM lags behind utilization. In response, the NATO Task Force HFM-195, Integrative Medicine Interventions for Military Personnel, was formed to evaluate the current status of CIM within the militaries of the NATO participating countries. Although the Task Force was primarily an exploratory committee, $\mathrm{CIM}$ or $\mathrm{IH}_{2}$ offers a new perspective on healthcare delivery in military organizations. Additional reviews and evaluations of $\mathrm{IH}_{2}$ with specific attention to the implementation of selected practices; development of educational programs for patients, providers, and policy makers; evaluations of clinical outcomes and best practices; establishment of collaborative research endeavors focused on cost-effectiveness of individual modalities; and new paradigms and models of care must be considered. Improved international military healthcare systems will ultimately benefit the readiness of troops, improve optimal performance of military personnel and organizations, and sustain financial stability of military organizations.

\section{AUTHOR DISCLOSURE STATEMENT}

COL Richard Petri, MC (MD), is an Active Duty Service Member in the United States Army and was appointed to the NATO panel HFM-195 ("Integrative Medicine Interventions for Military Personnel") as a technical team member. He was selected to the Chair of the panel in September 2013. Resources from the United States Army supported the travel expenses to the first four team meetings. 
The fifth meeting lodging expenses were partially supported by a grant from the Geneva Foundation. The remaining expenses were paid through personal resources. No competing financial conflicts exist. CPT Fred Zimmermann, MA, is a scientist working field of medical psychology at the University of Munich (LMU), and was appointed to the NATO panel HFM-195 ("Integrative Medicine Interventions for Military Personnel") as a technical team member for the duration of the Team. Resources from the German Ministry of Defense supported the travel expenses to the team meetings. From 2011 to 2013, the author conducted a research project with German Armed Forces, which was funded by the US-based Samueli Institute, as well as the Theophrastus Foundation and the Peter-Schilffarth Institute. However, the author did not receive any specific funding by governmental or non-governmental organizations to write this report. The author was never employed or paid by any military or religious organization. No competing financial conflicts exist. Marion Trousselard, MD, PhD, is an Active Duty Service Member in the French Army, and was appointed to the NATO panel HFM-195 ("Integrative Medicine Interventions for Military Personnel") as a technical team member for the duration of the Team. Resources from the French Ministry of Defense supported the travel expenses to the team meetings. The author did not receive any funding by governmental or non-governmental organizations to write this report. The author was never employed or paid by any military or religious organization. No competing financial conflicts exist. COL Richard Niemtzow, MC (Ret, MD, $\mathbf{P h D})$, is a retired Colonel from the United States Air Force. $\mathrm{He}$ is currently employee with the United States Department of Defense. He was appointed to the NATO panel HFM-195 ("Integrative Medicine Interventions for Military Personnel") as a technical team member. Resources from the Department of the United States Air Force supported the travel expenses to the first five team meetings. The sixth meeting was paid through personal resources. No competing financial conflicts exist.

\section{REFERENCES}

1. BrainyQuote. Hippocrates quotes. Online document at: www.brainyquote.com/quotes/authors/h/hippocrates.html Accessed December 28, 2014.

2. Weir T. Developing cultural fluency. Executive. May 1, 2004. Online document at: www.executive-magazine/buzz/developingcultural-fluency Accessed June 10, 2015.

3. Coulter ID, Ellison MA, Hilton L, Rhodes HJ, Ryan GW. HospitalBased Integrative Medicine: A Case Study of the Barriers and Factors Facilitating the Creation of a Center. Santa Monica, CA: RAND Corporation; 2007. Online document at: www.rand.org/ pubs/monographs/MG591 Accessed June 10, 2015.

4. Cant $S$, Watts P, Ruston A. The rise and fall of complementary medicine in National Health Service hospitals in England. Complement Ther Clin Pract. 2012;18(3):135-139.

5. Rakel D, Weil A. Philosophy of integrative medicine. In: Rakel D, ed. Integrative Medicine Philadelphia, PA: Elsevier; 2012: $2-11$.

6. Office of the Army Surgeon General. Pain Management Task Force Final Report May 2010Online document at: www.regenesisbio .com/pdfs/journal/Pain_Management_Task_Force_Report.pdf Accessed May 7, 2014.

7. Büssing A, Recchia DR. Spiritual and non-spiritual needs among German soldiers and their relation to stress perception, PTSD symptoms, and life satisfaction: results from a structural equation modeling approach. J Relig Health. Published online June 9, 2015.

8. Belard JL, Pock AR. Acupuncture and NATO. Med Acupunct. 2011;23(4):271-273.

Address correspondence to: COL Richard P Petri Jr., MD, FAAPMR, FAAIM Chairman, NATO HFM-195 Task Force

Integrative Medicine Interventions for Military Personnel United States Army El Paso, TX 79920

E-mail: richard.p.petri.mil@mail.mil; richard@ petrijr.com 